\title{
ŠIBUKAVA HARUMI I PRVI JAPANSKI NACIONALNI KALENDAR
}

Razmatra se pojava nacionalnog kalendara u Japanu i uloga Šibukave Harumija (Shibukawa Harumi) u prihvatanju prvog japanskog nacionalnog kalendara. Daje se evolucija kineskih kalendara u Kini, njihovo pojavljivanje u Japanu i razlozi za neaktivnosti u radu na reviziji kalendara u Japanu.

Ključne reči: Japan, kalendar, Šibukava Harumi (Shibukawa Harumi), kalendar Jokyo, kineski kalendari

\section{UVOD}

Kada se govori o kineskom uticaju na Japan obično se misli na pismenost (kinesko pismo), religiju (budizam, konfucijanizam, taoizam), sistem vladavine (uređenje države po kineskom uzoru). U ovom radu ćemo razmotriti drugi aspekt kineskog uticaja koji se ne analizira često; radi se o prenošenju kineskih kalendara i astronomskog znanja koje podloga za njegovu izradu. U skladu sa vladajućom doktrinom "Mandata Neba" kalendar je u Kini od perioda Čou (Chou 1046-256 god. pre n.e) imao ulogu obezbeđenja dinastije. U Japanu, kalendar prenet iz Kine u VI -VII veku nije imao istu ulogu pošto se vladajući sistem bazirao na drugim principima. Do XVII veka u Japanu su se koristili kineski kalendari, da bi posle Đokjo (Jokyo) kalendara (u upotrebi 1684-1753) koji je uradio japanski astronom Šibukava Harumi (Shibukawa Harumi), počeo razvoj nacionalnih, japanskih kalendara. Do 1873. godine, zvanični japanski kalendar bio lunarni, a od 1. januara 1873. godine u Japanu je počeo zvanično da se koristi evropski gregorijanski kalendar. Pored njega, godine su se i dalje računale od početka vladavine svakog novog cara i od uvođenja nove devize vladavine (nengo).

* m.jovic.dj@gmail.com 


\section{ŠIBUKAVA HARUMI}

Posle skoro hiljadu godina korišćenja kineskih kalendara, šogun Tokugava Cunajoši (Tokugawa Tsunayoshi 1646-1709) prihvatio je 1685. godine kalendar japanskog astronoma Šibukave Harumija (1639-1715) za zvanično korišćenje. Pre toga je carska uprava, nadležna za poslove kalendara, dva puta odbijala da prihvati ovaj kalendar.

Istaknuti japanski astronom i astrolog, stručnjak za kalendarsku astronomiju Šibukava Harumi ${ }^{1}$ rođen je 27. decembra 1639. godine, u gradu Kjoto u Japanu, u porodici Jasui (Yasui). Njegov otac je bio profesionalni igrač igre go. Kao dete, bio nazvan Rokuzo. Posle smrti oca 1652. godine, Šibukava je nastavio zanimanje svoga oca i prihvatio ime Santetsu. Od ranog detinjstva smatrali su ga vunderkindom, a on je pokazivao izuzetno razumevanje astronomije i talenat za proučavanje kalendara. Šibukava je obrazovanje dobio od mnogih vodećih naučnika svog vremena među kojima su Jamazaki Ansai (Yamazaki Ansai) sa kojim je proučavao konfucijanizam i doktrine šintoizma, kao i Junšo Matsura (Yunsho Matsuda) i Gentei Okanoi (Gentei Okanoi) od kojih je dobio stručnu obuku u oblasti metoda izrade kalendara.

Sa 30 godina, bio je na čelu Astronomskog društva koje je prvo u Japanu vršilo sistematsko posmatranje neba u Japanu. Kroz četiri godine, 1673. godine, na osnovu dobijenih podataka predložio je caru Reigenu (Reigen, vladao 1663-1687) reformu postojećeg kineskog kalendara Senmyo Reki. Car dao svoju saglasnost, ali prva verzija kalendara nije bila uspešna, jer nije predvidela pomračenje Sunca 1675. godine. 1683. poslao je dvoru ispravljenu verziju, ali je sledeće godine, 1684. dvor kao zvaničan kalendar prihvatio kalendar Daito (kin.Tatung) kineske dinastije Ming (1368-1644) za koji je Šibukava smatrao da nije ispravan. (Nakayama 1969:120). On tada šalje pismo šogunu Tokugava Cunajošiju i predlaže svoj kalendar Đokjo, nazvan po eri Jokyo (feb.1684-sep,1688), koji šogun prihvata, oduzimajući time dvoru prerogative stvaranja kalendara. Ovaj kalendar je važio je u Japanu do 1753. godine.

U razvoju sopstvenog sistema, Šibukava zadržava strukturu i teoriju kalendara iz 13. veka Shou-shih koji je izradio Guo Šouđing (Guo Shou-

1 Koristio je imena: Shibukawa Harumi, Shibukawa Shunkai, Yasui Santetsu II, Motoi Santetsu 
jing) u periodu dinastije Juan (Yuan) u Kini (1279-1368). On je takođe u kalendar Đokjo uključio razliku u geografskoj dužinu između Japana i Kine. Njegov kalendar predviđao kretanje Sunca i planeta preciznije od bilo kog kalendara urađenog u Kjotu u Birou za Jin-jang, na čelu koga je nasledno bila porodica Cućimikado (Tsuchimikado).

Tačna astronomska posmatranja, bila su neophodna za Šibukavin rad u reformi kalendara i on je sa entuzijazmom koristio veliki broj pribora, uključujući armilarnu sferu². Sa sklonošču ka posmatranju, on je sakupio materijal za niz karata zvezdanog neba, koje su objavljene 1670, 1677, 1699.

Šibukava je objavio više naučnih radova među kojima se ističe traktat iz matematičke astronomije "Riznica astrologije" (Tenmon keito) iz 1698. godine. U svojim radovima Šibukava je pokušao da očisti astrologiju od mnogih zabluda i tumačenja, za koje nije bilo praktične astronomske baze.

Posle postignutih rezultata, Šibukava je 1685. godine bio zvanično imenovan na dužnost državnog astronoma u Birou astronomije (Tenmongata). Preselio se u Edo 1686. godine i otvorio astronomsku opservatoriju. Unapređen je u klasu samuraja 1692. godine, a 1702. godine promenio je prezime u Šibukava, prezime porodice Jasui, pod kojim je najviše poznat. Šibukava Harumi završio svoj život u Edu 11. novembra 1715. godine.

\section{KINESKI KALENDARI}

Najstariji kineski kalendari javljaju se u dva oblika: kao sunčani (poljoprivredni) i sunčano-lunarni (dinastički) kalendari. Oba kalendara koncepirana su u periodu dinastije Hsia (Xia, 2100-1600 god. p.n.e.).

Sunčani kalendar određivao je najpogodnije periode za određene poljoprivredne radove i bazirao se na položaju Sunca koji se određivao gnomonom ${ }^{3}$. Ravnomernom podelom luka, između tačaka prolećne ravnodnevnice (srednja senka sunčanog sata - gnomona), letnje dugodnevnice

\footnotetext{
2 Armilarna sfera (lat. armilla - prsten, narukvica.) Sprava za merenje nebeskih tela.

3 Gnomon (grč. $\gamma v \omega ́ \mu \omega v$ - pokazivač) - najstariji astronomski uređaj u obliku vertikalnog predmeta (stub, štap kolona), koji omogućuje da se po najmanjoj dužini senke (u podne) odredi ugaona visina sunca.
} 
(najduža senka), jesenje ravnodnevnice (srednja senka) i zimske kratkodnevnice (najkraća senka), dobijala su se 12 ili 24 segmenta koji su određivali odgovarajuće sezone u poljoprivrednom kalendaru.

Mora se napomenuti da su i stari Japanci u periodu Jajoi (Yayoi 300 god. pre n.e - 300 god n.e) počeli da koriste sezonski kalendar, koji je verovatno uvezen iz Kine ili Koreje zajedno sa tehnologijom gajenja pirinča postupkom navodnjavanja. Međutim, Motoori Norinaga (1730-1801), poznati japanski naučnik, u radu iz 1782. godine "O istinskom kalendaru" (Shinreki ei) navodi da stari Japanci nisu imali nikakve instrumente i da su sezonske promene određivali na osnovu svojih posmatranja (Nakayama, 1969: 8).

Drevni sunčano-lunarni kalendar javlja se kao kalendar Hsia (prema prvoj kineskoj mitološkoj dinastiji). Počev od dinastije Šang (Shang, 1600-1050 god. pre n.e.) kineski kalendari su stvarani kao kombinacija lunarnog i solarnog ritma (kretanja). To su bili lunarno-solarni kalendari (yin-yang $l i$ ), u kojima se postupak određivanja po lunarnim mesecima dopunjavao korekcijom na sunčani ciklus uvođenjem "umetnutog meseca". Glavne teškoće u izradi lunarno-solarnog kalendara ležale su u činjenici da lunarni mesec (sred. vred. 29,53059 dana) i tropska godina (sred. vred. 365,24219 dana) ne sadrži ceo broj dana, a da se ceo broj lunarnih meseci ne uklapa u tropsku godinu, bez ostatka. Zato je jedan od glavnih zadataka stvaralaca lunarno-solarnog kalendara bila sinhronizacija sunčevog ciklusa i broja lunacija (vremena između dve iste faze Meseca). Zadatak sinhronizacije Kinezi su rešili naizmeničnim smenjivanjem dugih i kratkih meseci, po 29, odnosno 30 dana. U dinastiji Šang, mesec od 29 dana nazivao se "mali mesec", a od 30 dana "veliki mesec". (Ĺđlíćlíâ Á.Ĺ. “Ęrélíär̈đü” http://www.synologia.ru/a/\%, 27.09.2019.)

Razmatrajući kineske kalendare, japanski astronom Šigeru Nakajama (Shigeru Nakayama), navodi da je u Kini za dve hiljade godina izvršeno više od pedeset reformi kalendara, dok je za to vreme na Zapadu izvršena samo jedna velika reforma - Gregorijanska. Zbog čega su Kinezi bili zabrinuti, šta ih je primoravalo da ulažu velike napore u stvaranje kalendara? Nakajama navodi dva osnovna razloga: prvi je, vladajuća doktrina "kulta Neba", a drugi stalna težnja ka usavršavanju kalendara.

1. Državna ideologija u Kini od perioda dinastije Šang (1600-1050) god. pre n.e. vezuje se za pojam Neba ( $t$ `ien ). U starim kineskim tekstovima pojam Neba se tumačio na više načina od kojih je za ovaj rad značajno 
“vrhovno božanstvo, najviša božanska moć” (Titarenko, 1994:329) . Nebesa su birala vladara dajući mu "Mandat", a on je bio dužan da vlada u skladu sa nebeskim pravilima. $\mathrm{Na}$ ispunjenje ili neispunjenje ovih pravila ukazivale su nebeske pojave tako da su nepovoljne pojave na nebu ukazivale na loše ponašanje vladara.

Posle značajnih promena u državi, a posebno posle smene dinastija, novi imperator je morao da menja upravni aparat, a posebno zvanični kalendar - da bi potvrdio da je došlo do uspostavljanja novog poretka, novog rasporeda nebeskog uticaja, što je podrazumevao novi Mandat.

Ova ideja bila je dobro korišćena u vreme dinastije Han (Han 206 p.n.e. -220 n.e.). Nakajama navodi da je car Vu ( $W u$, vladao 140-87 godine pre n.e.) bio obavešten od svojih savetnika da mora odmah da revidira kalendar i da promeni boju ceremonijalne odeće kako bi bilo jasno da je njegova vladavina zasnovana na stvarnom Mandatu. Rezultat toga bio je carski dekret, kojim je usvojen kalendar Taichu (104. god pre n.e.) (Nakayama, 1969:63).

Važnost kalendara za politički sistem dao je proučavanju kalendara takav značaj da istorija kineske astronomije predstavlja u najvećoj meri istoriju formiranja kalendara. Naučna kosmologija bila je zapostavljena i zaboravljena.

Sa vremenom, politički značaj reformi kalendara postepeno se smanjuje. Mada su neki vladari pokretali reforme da proglase novi poredak i da na taj način dobiju podršku naroda, klasična identifikacija revizije kalendara sa promenom dinastije u velikoj meri se izgubila u vreme dinastije Severni Vei (Wei 386-534 god. n.e.) i kasnijih Severnih dinastija.

2. Od dinastije Tang (618-806) motiv za reformu kalendara bio je, jednostavno, ispravka kalendara, usaglašavanje sa posmatranim nebeskim pojavama. Zbog toga su reforme vršene svaki put kada je uočena neka pogreška. Kineskim kalendarima nisu bili zadovoljni kao običnim kalendarom u kome su Sunce i Mesec bili usaglašeni za građansku upotrebu, već su pokušavali da uključe neprirodna kretanja Sunca i Meseca i periodična kretanja pet planeta. Naučnici tada nisu bili posebno zainteresovani za istraživanje. Njihov naučni zadatak bio je da se isprati vidljivi položaj nebeskih tela i da se dobije maksimalno moguće slaganje između kretanja nebeskih tela i lunarno-solarnog kalendara pomoću algebarskih metoda, a ne geometrijskih postupaka. 


\section{KINESKI KALENDARI U JAPANU}

Kineski kalendari u Japanu javili su se pri kineskim dinastijama Sui (581-618) i Tang (618-906) u periodu Asuka (552-710) u vremenu kada je uticaj kineske kulture tek počeo da se uspostavlja, od koje su Japanci, od početka, prihvatali samo ono što je odgovaralo njegovom nacionalnom interesu. Uticaj kineske kulture trajao je do XVII veka sa većim ili manjim intenzitetom, pri čemu se mogu izdvojiti tri osnovna perioda: do VII veka - period pojave kineske kulture u Japanu; od VII do IX veka - vladavina kineske kulture; od X veka do početka XVI veka - opadanje kineskog uticaja.

\section{Prvi zapisi o kalendaru и Japanu}

Hronologija pojave prvog kalendara u Japanu zabeležena je u japanskoj istorijskoj hronici Nihon Šoki (Nihon Shoki) ili Nihongi (Nihongi), završene 720. godine pod rukovodstvom princa Tonerija i učešćem $\mathrm{O}$ no Jasumaroa ( $\hat{O}$ no Yasumaro).

Prvi zapisi o kalendaru nalaze se u XIX svitku za 553. godinu (14. godina vladavine cara Kimeija (Kimei), proleće, 6.mesec) postoji zapis da se u poruci Kimeija, cara države Jamato, vanu Pekčea (Paekche) kaže “... zameni lekare, gatare i poznavaoce kalendara. Došlo je vreme da se navedeni ljudi menjaju. Neka se zamenjeni pridruže (našem) poslaniku. Neka se takođe pošalju knjige za proricanje, kalendari i razni lekovi" (Aston, vol II: 1896: 68).

$\mathrm{U}$ istom svitku za 554. godinu (15. godina, 2. mesec) navodi se da je, u skladu sa naredbom cara, iz Pekčea došlo više učenih ljudi koji će zameniti postojeće, među kojima profesor proricanja Van Tojan (Wan Tonyang), profesor kalendarnih poslova Van Poson (Wan Poson). (Aston, vol II: 1896: 72).

Dalje, za 602. godinu, (10. godina vladavine carice Suiko, zima, 10. mesec) navodi se da je "stigao monah iz Pekčea po imenu Kvaluk (Kwalleuk). On je doneo 40 knjiga o kalendaru, astrologiji, geografiji, kao i knjige o umetnosti i magiji. Tada su izabrana tri ili četiri učenika, koji su počeli da se obučavaju kod Kvaluka: Oćin no Fumibito (Ochin no Fumibito), studirao kalendar; Otomo no Suguri (Otomo-no Suguri) studirao astrologiju i umetnost nevidljivosti i magiju, Jamaširo no Omi (Yamashiro-no Omi) 
proučavao magiju. Svi su učili sa velikim požrtvovanjem. (Aston, vol II: 1896: 126).

Za uvođenje kineskog kalendara najznačajniji je zapis u XXX svitku iz 690. godine (11.mesec, 11. dan.) "Po naređenju vladarke (carice) počela je upotreba kalendara genka (kin.Yuan-kia) i giho (I-feng)." (Aston, vol II: 1896: 400).

U Japanu su korićeni sledeći kineski kalendari, u navedenim periodima:

- Genka (jap. Genka, kin. Yuan-chia li) 692-696 godine

- Gihô (jap. Giho, kin. Yi-feng li ) 697-763 godine

- Taien (jap. Taien, kin. Daien ili Dayan ili Dayan) 764-862 godine

- Goki (jap. Goki, kin. Wuji li) 858-861 godine

- Semjo (jap. Senmyo, kin. Xuanming) 862-1685 godine

Japanci su kopirali kinesku praksu u astronomiji, kao i u drugim oblastima. U početku je bila prihvaćena kao formalni aspekt političke organizacije. 628. godine usvojen je kineski sistem za merenje vremena i napravljen je vodeni sat. 675. godine počela je da radi astrološka opservatorija. 702. godine bio je objavljen Taiho, Građanski zakonik sa normama koje regulišu upravu i obrazovanje u astrologiji - astronomije i kalendara. Između 690. i 861. kineski kalendari su usvojeni i revidirani u četiri puta. (Nakayama, 1969:10)

U periodu Tokugava (1600-1848) japanski naučnici počeli su da modifikuju kineske kalendare prilagođavajući ih potrebama Japanaca. Tada su nastali japanski kalendari:

- Đokjo (Jokyo) u upotrebi 1685-1755 godine

- Horjaku (Horyaku) u upotrebi 1755-1798 godine

- Kanse (Kansei) u upotrebi 1798-1844 godine

- Tenpo (Tenpo) u upotrebi 1844-1872 godine

Prilagođavajući se zapadnoj tehnologiji u periodu Meiđi (18481912), Japan je od 1. januara 1873. počeo da koristi gregorijanski kalendar zadržavši pri tome i nengo sistem računanje godina od početka vladavine svakog novog vladara.

Pored gregorijanskog, u Japanu su postojala još četiri različita načina brojanja godina (Bramsen, 1910:1-6): 
(a) prema godinama vladavine careva

(b) prema godinama perioda (nengo)

(c) prema šestdesetogodišnjem ciklusu

(d) neprekidno, počev od prve godine vladavine prvog cara Đimua (Jimmu Tenno).

\section{Uslovi za prihvatanje kalendara}

Prihvatanje kineskih kalendara u periodu Asuka (592-710) vezano je sa jedne strane za uspostavljanje japanske državnosti po kineskom uzoru, a sa druge za ujednačavanje perioda održavanja verskih praznika posebno povezanih sa fazama uzgajanja pirinča i ubiranja poreza od zemljoradnje $u$ celoj zemlji. Stvaranje državnosti praćeno je velikim reformskim promenama koji su počele uvođenjem konfucijansko-budističkih normi u društvenu sredinu u obliku Ustava Šotoku Taišija 604. godine (Shōtoku Taishi, 574-622), a nastavljene su sređivanjem odnosa u administraciji uvođenjem sistema rangova i zakonodavnim aktima reformi Taika (646) i Zbornika zakona Taihorjo (Taihoryo) (701-702). (Marković, Jović 2010: 52).

U okviru kodeksa Jororjo (Yororyo) revidirane verzije zakonika Taihorjo (Taihoryo) (završene 718, ozvaničene 757.) predviđeno je formiranje astrološke uprave, Biroa za Jin-jang (Onmyō-ryō, On'yō-ryō ili On'yo no tsukasa) u čijem opsegu su bila astrološka predviđanja, astronomska posmatranja (Sunca, Meseca, planeta, zvezda), sastavljanje kalendara, posmatranja kretanja oblaka i vetrova i izveštavanje vladara tajnom porukom o svim neuobičajenim pojavama. Ukupno, osoblje se sastojalo od 82 čoveka. Sansom specificira osoblje na sledeći način:

Uprava

Odeljenje proročanstva

Odeljenje kalendara

Odeljenje posmatranja neba

Odeljenje merenja vremena

Pomoćna služba
Direktor i 4 saradnika

12 saradnika i 10 učenika

1 visoki stručnjak i 10 studenata

1 visoki stručnjak i 10 studenata

1 visoki stručnjak i 10 studenata

22 osobe

Sansom napominje da su značajni položaji u ovoj upravi ubrzo postali nasledni porodicama Abe i Kamo (Sansom 1932: 81)

Struktura Biroa za Jin-jang pokazuje da u Japanu nisu prihvatili administrativno odvajanje proročanstava od stvaranja kalendara, istraživanja 
astronomije, kao i merenja vremena kao što je to bilo u Kini, jer u Japanu nije prihvaćen "mandat Neba" u kineskom obliku. Astronomske promene tumačile su se u Kini kao upozorenje da je vladar prekršio želju Neba i on je bio izuzetno zabrinut zbog prirodnih znamenja. Da se uoče astronomski predznaci i da se što pre preduzmu određene protivmere, vladar je imenovao dvorske astronome i zahtevao od njih da vrlo pažljivo i temeljno kontrolišu nebo. Astronomi su vladaru obezbeđivali podatke za procenjivanje i često su mu pomagali u političkim odlukama.

U Japanu su nauka i predskazanje proučavani u jednoj upravi, Birou za Jin-jang. U kineskoj astrologiji najviši zvanični status imao je kalendar - stvaranje novog (sledećeg) i beleženje događaja tj. merenje vremena, dok su predskazanja imala najniži status. U Japanu naprotiv, predskazanja i astrologija su imala najviši status ${ }^{4}$, a tek posle stvaranje kalendara status je dobilo i merenje vremena.

Po prvi put se astrološka uprava Japana pominje u analima Nihongi pod 4. godinom vladavine cara Temua (Teтmu, 675) gde se kaže da su prvog dana Nove godine [zvaničnici] Onmyō-ryō predstavili vredne poklone caru.

\section{JAPANSKI NACIONALNI KALENDAR}

\section{Preduslovi za promenu}

Posle prihvatanja kalendara Semjo Senmyo (kin. Hsuan-ming) 862. godine, u Japanu je počeo dug period nezainteresovanosti za reforme kalendara, delimično zbog gubitka kontakta sa kineskom dvorskom astronomijom, a delom zbog nedostataka stručnjaka sa potrebnim znanjem i veštinama. Iako je predlog o reviziji kalendara bio unet po isteku ovog vremena, reforma nikada nije bila sprovedena. Neadekvatnost kalendara Hsuan-ming postala je tokom vremena očigledna. Vrednost tropske godine

$4 \quad$ Kineski principi Jin-jang i pet elemenata bili su u Japanu poznati samo među specijalistima na dvoru. Za obične Japance ova filozofija je bila teška za razumevanje. Na taj način, čisto japanski aspekti prakse određivanja budućnosti (sudbine) bili su razvijeni u obliku popularne veštine Onmy $\bar{o}-d \bar{o}$. Ona predstavlja skup verovanja dobijenih iz različitih izvora: predviđanja, geomantija, egzorcizam, kompleks kalendara i proračuna o smerovima i kretanjima. Razna književna i umetnička dela dvorske aristokratije pokazuju da su njihovi javni i privatni životi bili strogo uslovljeni zabranama Onmyō-dō. Određivanje (izračunavanje) sudbine privlačilo je ljude, ali ne i sama teorija. (The Japanese Calendar https://www.ndl.go.jp/koyomi/e/, 25.07.2019.) 
ugrađene u njega (365.2446 dana) dosta se razlikovala od stvarne vrednosti (365.2422 dana), što je, posle više od osam stotina godina neprekidne upotrebe kalendara, dovelo do razlike od skoro dva dana. Razlika geografske dužine između Kine i Japana takođe je bila zanemarena u predviđanju pomračenja. I pored toga, kalendar je u Japanu ostao nepromenjen, dok su u Kini kontinualno vršene potrebne promene.

Još jedan primer japanske nezainteresovanosti za pitanja kalendara bilo njihovo ograničeno korišćenje astronomskih instrumenata. U Tang Kini gnomon i vodeni sat je su se široko koristili u astronomske svrhe, dok su se u Japanu vodeni satovi su verovatno koristili samo za merenje vremena. Oni nisu bili korišćeni kao provera kalendara niti u astronomskim observatorijama za beleženje kretanja nebeskih tela. Gnomon je bio donet na japanski dvor 736 godine, ali su zapisi o njegovom korišćenju do perioda Tokugava oskudni. Ovi alati za merenje vremena bili su u rukama vladine administracije i za ekskluzivnu upotrebu. Ako bi pojedinac koristio neki od njih bio osuđen na kaznu od godinu dana.

Osim toga, Japanci nisu otišli dalje u teorijskom delu izrade kalendarskog, nego su tumačili radove koji su im dostupni. Nakajama ističe da su bili zadovoljni proučavanjem knjiga, nisu posmatrali i ispitivali kretanje nebeskih tela, niti su mogli shvatiti teorijsku osnovu kalendara (Nakayama, 1969: 72).

Posle dva veka zavisnosti od kineske misli Japan je izgubio kontakt sa Kinom. Samo su trgovci i budistički monasi održavali vezu sa kontinentom. U isto vreme u Japanu je došlo do velikih unutrašnjih društveni promena. Kalendar je ostao netaknut tokom skoro osam vekova, bez obzira na potrebu i tradiciju čestih revizija kineskih kalendarskih sistema.

Za neaktivnost revizije kalendara u Japanu postoji nekoliko objašnjenja. Revizija zvaničnog kalendara u Japanu bio je događaj od velikog političkog značaja, a ne samo tehnički problem. Osim toga, tradicija u Japanu je nalagala da je rad na kalendaru monopol carskog dvora, dok je stvarna politička i upravna vlast bila u rukama Šoguna ${ }^{5}$. Čak i ako astronom dobro

$5 \quad$ Prihvatanje kalendara bila je prerogativ carskog dvora od carice Suiko 692. godine. Kalendar Semjo (Senmyo) prihvaćen je 862. godine za vreme vladavine cara Seve (Seiwa), dok je prvi šogunat formirao Minamoto Joritomo (Minamoto Yoritomo) 1192. godine i preuzeo svu izvršnu vlast. Međutim, odluka o reviziji kalendara ostala je i dalje u rukama carskog dvora. 
poznaje nedostatake "tekućeg kalendara", on cěe morati da odmeri svaki predlog za reformu kalendara pošto se to može smatrati kritikom vlasti. U takvim okolnostima, odlučnost i samopouzdanje su isto tako važni kao i poznavanje astronomije.

Iako je do sedamnaestog veka razlika u trajanju tropske godine bila skoro dva dana, ona nije stvarala nikakve posebne neprijatnosti ili konfuzije u svakodnevnom životu. Ovakva mala razlika nije mogla da utiče na poljoprivredu u bilo kakvom značajnom stepenu. Štaviše, prilikom određivanja poljoprivrednog rasporeda, seljaci su se oslanjali više na iskustvo nego formalne godišnje kalendare. Predviđanje pomračenja postaje izuzetno netačno, ali je greška u lunarnom mesecu bila relativno mala. Ako su postojali motivi za reforme, onda je njihovo uvođenje od strane vlasti predstavljalo jačanje carske mocěi pružanjem preciznog nacionalnog kalendara za upotrebu.

Zbog toga samo tehničko znanje nije bilo dovoljno za sprovođenje reformi kalendara. Od velikog značaja bila je i diplomatska sposobnost, dovoljna da ubedi važne političke ličnosti o značaju reforme. Šibukava Harumi je bio čovek sposoban za takav težak zadatak.

Jedan od najvažnijih uticaja na Harumija da se prihvati odluke za stvaranje novog, japanskog kalendara bio je esej kineskog astronoma Li Ciana (Li Qian, 1223-1302). Teorijske postavke kalendara Shou shi (Shoushih liyi) (Trimble V. et all eds, 2007:450). Kalendar Shou-shih bio je usvojen u Japanu sa oduševljenjem i posle 1670. godine je više puta se preizdavao u japanskim publikacijama. Mnogi njegovi komentatori, kao što su Seki Takakazu (Seki Takakazu) i Takebe Katahiro (Takebe Katahiro) bili su su prvoklasni matematičari. Kalendar se u Japanu pojavio rano, ali ga zbog slabog poznavanja matematike nisu mogli razumeti pre Tokugava perioda.

Usvajanjem kalendara Đokjo (Jokyo) 1684. godine, vlada Šogunata je preuzela nadležnosti u izboru kalendara. Nominalno, dvor je i dalje imao punomoćje za izdavanje kalendara, ali su astronomi šogunata bili u obavezi da vrše sve tehničke poslove oko naučnih delova kalendara (astronomske tablice, proračuni i sl.).

Posle ovog uspeha, Šibukava Harumi je imenovan za službenog astronoma (tenmongata) u šogunatu u Edu. Od tada, vlada šogunata Tokugava održava stalne astronomske funkcije, nezavisno od dvora. Ova mesta su takođe bila nasledna, ali pod feudalnim režimom, ova situacija uopšte nije bila neuobičajena - čak ni za tehničke pozicije. 
Rad Šibukave Harumija je bio u potpunosti zasnovan na kalendarskom traktu Shou-shih iz 1282, koji je generalno bio prihvacěen kao astronomska klasika u periodu Tokugava. Kineske reforme u ovom periodu proglasile su dve kalendarske reforme, dva kalendara, Ta-t'ung (1368) i Shih-hsien (1644). Shin-hsien bio je bio zvanični kalendar koje su sastavljali evropski jezuiti. Ovo bi nesumnjivo imalo veliki uticaj na Harumija, da mu je on bio dostupan u celini. Ali, izgleda da je on imao samo fragmentarne informacije, samo kalendare koji su bili godišnje distribuirani. Najvredniji za njegove potrebe bio je kalendar - traktat Shou-shih -li izdat četiri veka ranije.

Što se tiče zapadnih astronomskih radova, skoro jedini izvor koji je on imao bio je T'ien-ching huo-wen. Iako je šematski pristup ovog rada bio nov za dalekoistočnu tradiciju, njegovi grubi parametri nisu bili korisni za praktične proračune. Kada je Harumi komentarisao da "mada je Zapadna teorija privlačna, ona se ne može primeniti u praksi”, njegova procena je bila opravdana zbog ograničene informacije koja mu je bila dostupna. Pošto je bio vatreni reformator kalendara, malo je verovatno da je govorio iz predrasuda.

Instrumenti Šibukave Harumija bili su znatno skromniji od instrumenata kineskog astronoma Guo Šouđinga (Guo Shoujing). Vrednost Harumijevih posmatranja nalazi se u njegovoj zameni kineske geografske dužine i širine japanskom. Kalendar Đokjo je imao nekoliko manjih poboljšanja, ali Harumi nije mogao da izvrši velike inovacije.

Za Japance je bilo psihološki važno da se prekine sa dugogodišnjom zavisnošću od kineskih kalendara. Harumi nije bio stalno pod uticajem kalendara Shou-shih, već je osećao da imao pravo da ga kritikuje u okviru svojih mogućnosti. Zato, Đokjo kalendar ne izlazi iz okvira tradicionalnog kineskog kalendara. U samoj Kini, ovu strukturu promenila je jezuitska aktivnost XVII veku. Japanci su s druge strane, počeli da razvijaju sopstvenu nauku u potpunosti u okviru tradicionalnih formulacija.

\section{ZAKLJUČAK}

Stvaranje nacionalnog japanskog kalendara predstavlja prevazilaženje kineskog uticaja u ovoj oblasti intelektualne delatnosti i početak bržeg razvoja u oblasti astronomije i primenjene matematike. Kineski uticaj trajao je oko hiljadu godina i u tom periodu (692-1685) Japanci su prihvatili pet kineskih kalendara, ali za razliku od drugih društvenih oblasti, oni u oblasti kalendara nisu vršili prilagođavanje svojim uslovima, već su kalendare kori- 
stili u nepromenjenom obliku u kome su stigli iz Kine. Zato su postojala tri osnovna razloga: prvi je, da u Japanu nebeske promene nisu imale odlučujući uticaj na vladajuću dinastiju kao u Kini i zato nije postojao imperativ podešavanja kalendara tekućem stanju; drugi, da Japan nije imao odgovarajuće školovane kadrove i potrebnu literaturu i opremu za astronomska proučavanja; i treći, da struktura vlasti nije bila naklonjena bilo kakvim promenama, jer su se svi zahtevi za promenama mogli smatrati kritikama vlasti. Tek kada su stvoreni naučni kadrovi sposobni da se izbore za svoje stavove, došlo je do promene kineskog kalendara i pojave nacionalnog, japanskog. U tome je glavna zasluga japanskog astronoma Šibukave Harumija.

\section{LITERATURA}

Aston W.G. (1896). Nihongi vol II. London: Kegan Paul, Trench Trubner,\& Co, Bramsen W. (1910). Japanese Chronology and Calendar. In Japanese Chronological tables from Tai-kwa 1st years to Mei-ji 6th years, Tokyo: Seishi Bunsha.

Buckley S, ed. (2006). Encyclopedia of Contemporary Japanese Culture. New York: Routledge.

Harley J.B, Woodward D, eds. (1994). Cartography in the Traditional East and Southeast Asian Societies, volume 2, book 2. Chicago: University of Chicago Press.

Hockey Tech. ed. (2011). Biographical Encyclopedia of Astronomers. New York: Springer.

Lankford J. ed. (1997). History of Astronomy : An Encyclopedia, New York: Routledge.

Loewe M., Shaughnessy E.L. (2006). The Cambridge History of Ancient China. Cambridge: Cambridge University Press.

Marković Lj, Jović M. (2010). Japan od predanja do zapisa. Beograd: Filološki fakultet Unoverziteta.

Miyajima K. (1988). Influence of Chinese Astronomy in Japanese Culture. Vistas in Astronomy, Vol. 31, pp. 805-808.

Nakayama S. (1969). A History of Japanese Astronomy Chinese Background and Western Impact. Harvard University Press.

Sansom G.B. (1932). Early Japanese law and administration, The Transaction of the Asiatic Society of Japan, Second series, vol IX, pp 67-110. 
Orchiston W, Nakamura T, Strom R. eds. (2011). Highlighting the History of Astronomy in the Asia-Pacific Region, New York: Springer.

The Japanese Calendar https://www.ndl.go.jp/koyomi/e/ [25.07.2019.]

Trimble V. et all eds. (2007). Biographical Encyclopedia of Astronomers. Springer Science. pp 450-451

Wang L. (1988). The Ancient Japanese Lunisolar Office and the Ancient Calendar. Vistas in Astronomy, Vol. 31, pp. 811-817.

Володомов Н.В. (1987). Каленяарь, иррошлое, насйоящее,буяущее. Москва: Наука.

Голыгина К.И. (2003). Звезяное небо и «Книїа иееремен» Москва: РАН.

Еремеев В.Е. Каленяарь - http://www.synologia.ru/a/\%D0\%9A\%D0\%B0\% D0\%BB\%D0\%B5\%D0\%BD\%D0\%B4\%D0\%B0\%D1\%80\%D1\%8C [28.07.2019.]

Климишин И.А. (1985). Каленgарь и хронолоїия. Москва: Наука.

Нихон сёки Анналы Яйонии (1997). Пер. и коммент. Л. М. Ермаковой и А. Н. Мещерякова. Т 2. Свитки ХУІІ XXX. СПб.: Гиперион.

Селешников С.И. (1977). Истиория каленgаря и хронолоіия. Москва: Наука. Титаренко М.Л. гл.ред (1994). Кийайская философия, Энциклойеgический словарь. Москва: Мысль.

\section{Marina Jović Đalović}

\section{SHIBUKAWA HARUMI AND THE FIRST JAPANESE CALENDAR}

\section{Summary}

The appearance of the National calendar in Japan and the role of Shibukawa Harumi in the adoption of the first national calendar of Japan are considered. An overview of the evolution of Chinese calendars in China is given, their appearance in Japan, and the reasons for inactivity in the revision of the calendar in Japan. calendars

Keywords: Japan, calendar, Shibukawa Harumi, Jokyo calendar, Chinese 